\title{
Antagonistic roles of Notch and p63 in controlling mammary epithelial cell fates
}

\author{
Ö Yalcin-Ozuysal ${ }^{1,4}$, M Fiche ${ }^{2}$, M Guitierrez ${ }^{1}$, K-U Wagner ${ }^{3}$, W Raffoul ${ }^{2}$ and C Brisken ${ }^{\star, 1}$
}

The breast epithelium has two major compartments, luminal and basal cells, that are established and maintained by poorly understood mechanisms. The p53 homolog, p63, is required for the formation of mammary buds, but its function in the breast after birth is unknown. We show that in primary human breast epithelial cells, maintenance of basal cell characteristics depends on continued expression of the p63 isoform, $\Delta \mathrm{Np} 63$, which is expressed in the basal compartment. Forced expression of $\Delta \mathrm{Np} 63$ in purified luminal cells confers a basal phenotype. Notch signaling downmodulates $\Delta$ Np63 expression and mimics $\Delta$ Np63 depletion, whereas forced expression of $\Delta \mathrm{Np} 63$ partially counteracts the effects of Notch. Consistent with Notch activation specifying luminal cell fate in the mammary gland, Notch signaling activity is specifically detected in mice at sites of pubertal ductal morphogenesis where luminal cell fate is determined. Basal cells in which Notch signaling is active show decreased p63 expression. Both constitutive expression of $\triangle \mathrm{Np} 63$ and ablation of Notch signaling are incompatible with luminal cell fate. Thus, the balance between basal and luminal cell compartments of the breast is regulated by antagonistic functions of $\Delta \mathrm{Np} 63$ and Notch.

Cell Death and Differentiation (2010) 17, 1600-1612; doi:10.1038/cdd.2010.37; published online 9 April 2010

The breast epithelium consists of two cell compartments, luminal and basal. Luminal cells are connected by tight junctions and form a single layer of polarized epithelium around the ductal lumen. They express cytokeratin (CK) 18 and high levels of heat-stable surface antigen CD24. ${ }^{1-2}$ About a third of the luminal epithelial cells express the nuclear hormone receptors, estrogen receptor- $\alpha(E R \alpha)$ and progesterone receptor, ${ }^{3}$ and act as sensor cells by detecting steroid hormones and translating this systemic stimulus into local autocrine/paracrine signals. ${ }^{4}$

The basal compartment comprises all the cells that do not touch the lumen, these include progenitors and myoepithelial cells. ${ }^{2}$ The latter are contractile, form a meshwork around the luminal cells, and have a role in milk ejection during lactation. Basal cells express CK14 and have extensive contact with the basal lamina, dependent on high expression of the adhesion molecules integrin $\beta 4$ (ITGB4) and $\alpha 6$ (ITGA6). ${ }^{5-6}$ Human basal and luminal cells can be separated based on differential expression of the surface antigen $\mathrm{CD} 10 ;^{1}$ their murine counterparts can be distinguished by their CD24 immuno phenotype, with basal cells expressing low $\left(\mathrm{CD} 24^{\mathrm{lo}}\right)$ and luminal cells expressing high levels $\left(\mathrm{CD} 24^{\mathrm{hi}}\right){ }^{2}{ }^{2}$

Fluorescence-activated cell sorting (FACS) experiments with mouse mammary epithelial cells (MMECs) have shown that $\mathrm{CD} 24^{\mathrm{lo}}$ populations with high expression of ITGB1 (CD29 ${ }^{\text {hi }}$ ) or ITGA6 (CD49hi) are enriched for cells with in vivo reconstitution potential. ${ }^{7-8}$ It is thought that mammary stem cells of $\mathrm{CD} 24^{\mathrm{lo}} \mathrm{CD} 29^{\mathrm{hi}} / \mathrm{CD} 49 \mathrm{f}^{\mathrm{hi}}$ phenotype, give rise, either directly or through intermediary cell stages, to bipotent progenitors. These in turn generate basal/myoepithelial and luminal progenitors that differentiate into mature myoepithelial cells and different types of luminal cells that can be alveolar or ductal and ER $\alpha$ positive or negative. ${ }^{9}$

Recently, Notch signaling has been implicated in controlling stem cells and lineage commitment in different ways. ${ }^{10-12}$ Binding of ligands, Jagged1 and 2, and DII1, 3, and 4 expressed on the surface of neighboring cells leads to cleavage of Notch receptors (1-4) and release of the Notch intracellular domain, which converts the DNA-binding protein $\mathrm{CBF} 1 / \mathrm{Rbp}-\mathrm{J} \kappa$ from a repressor to an activator of transcription. ${ }^{13}$ On the one hand, Notch activation promoted selfrenewal of stem cells, proliferation of progenitor cells, and commitment to the myoepithelial lineage in human breast epithelial cells (HBECs), as assessed by the mammosphere assay. ${ }^{11}$ On the other hand, cell separation experiments combined with colony-forming assays suggested that Notch signaling restricts bipotential human progenitors to a luminal cell fate ${ }^{10}$ and downmodulation of Rbp-J $\kappa$ in mouse progenitor

${ }^{1}$ Ecole Polytechnique Fédérale de Lausanne (EPFL), ISREC - Swiss Institute for Experimental Cancer Research, Lausanne, Switzerland; ${ }^{2}$ Centre Hospitalier Universitaire Vaudois, Lausanne, Switzerland and ${ }^{3}$ Eppley Institute for Research in Cancer and Allied Diseases, University of Nebraska Medical Center, Omaha, $\mathrm{NE}$, USA

${ }^{*}$ Corresponding author: C Brisken, Ecole polytechnique fédérale de Lausanne (EPFL), ISREC - Swiss institute for experimental cancer research, NCCR Molecular Oncology, SV2.832 Station 19, CH-1015 Lausanne, Switzerland. Tel: + 41 (0)21 6930781 or + 41 (0)21 6930762 ; Fax: + 41 (0)21 693 07 40;

E-mail: cathrin.brisken@epfl.ch

${ }^{4}$ Current address: Department of Molecular Biology and Genetics, Izmir Institute of Technology, 35430 Izmir, Turkey.

Keywords: breast epithelium; cell fate; Notch; p63; progenitor

Abbreviations: BrdU, bromodeoxyuridine; CK, cytokeratin; ER, estrogen receptor; FACS, fluorescence-activated cell sorting; HBEC, human breast epithelial cell; ITGA6, integrin $\alpha 6$; ITGB4, integrin $\beta 4$; MMEC, mouse mammary epithelial cell; MMTV, mouse mammary tumor virus; NICD, Notch1 intracellular domain; SMA, smooth muscle actin; TEB, terminal end bud; TNR, transgenic Notch reporter; WT, wild type.

Received 25.9.09; revised 08.2.10; accepted 08.3.10; Edited by V De Laurenzi; published online 09.4.10 
cells increased their reconstitution potential. ${ }^{12}$ Notch signaling has long been established as oncogenic in the mammary epithelium as a mouse mammary tumor virus (MMTV) insertion resulting in a truncated, constitutively active Notch4 caused mammary tumors at high frequency. ${ }^{14}$ It has also been implicated in human breast carcinogenesis, with expression of its inhibitor Numb being lost in $50 \%$ of mammary carcinomas. ${ }^{15}$ Increased expression of Jagged-1 has been associated with a bad prognosis. ${ }^{16}$ Whether the dual role of Notch, alternatively oncogenic or differentiation inducing, depends on cellular context, developmental stage, hormonal milieu, and/or different receptors with Notch1 and 3 implicated in differentiation ${ }^{10}$ and Notch4 controlling stem cells ${ }^{10-11}$ remains to be addressed. Indeed, little is known about the downstream mechanisms involved in Notch function in the breast.

p63, similar to its homologs p53 and p73, is a sequencespecific DNA-binding protein. ${ }^{17}$ Expression from different promoters produces two protein isoforms, TAp63 or $\Delta \mathrm{Np63}$, which either contain or lack the $\mathrm{N}$-terminal transactivation domain. Each isoform has three different $\mathrm{C}$-terminal variants due to differential mRNA splicing $(\alpha, \beta$, and $\gamma) \cdot{ }^{17}$ Mutations in $p 63$ are implicated in a broad spectrum of human syndromes with deficiencies in epithelial homeostasis. ${ }^{18}$ Among them is the limb-mammary syndrome, involving hypoplasia/aplasia of the mammary gland and nipple, in which mutations in exons 13 and 14 lead to a frameshift mutation resulting in a truncated protein. ${ }^{18}$

Deletion of $p 63$ in the mouse germ line severely impairs skin development and blocks the formation of mammary glands and other ectodermal derivatives. ${ }^{19-22}$ This circumstance prevented the analysis of p63 function in the mammary gland. p63 is expressed in the basal compartment of many epithelia ${ }^{17,20,22}$ including the breast. ${ }^{23}$ It has been implicated in maintaining the proliferation potential of stem cells in the epidermis $^{21}$ through the $\Delta$ Np63 isoform, whereas TAp63 is required in maintaining integrity of the female germ line. ${ }^{24}$ The molecular mechanisms underlying p63 function involve changes in transcription of cell adhesion genes including different integrins. ${ }^{25}$

Here, we examine p63 function in primary HBECs from multiple donors of different genetic backgrounds, and show a

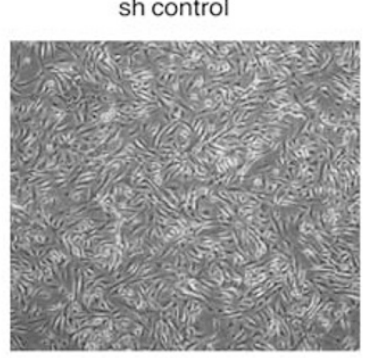

b

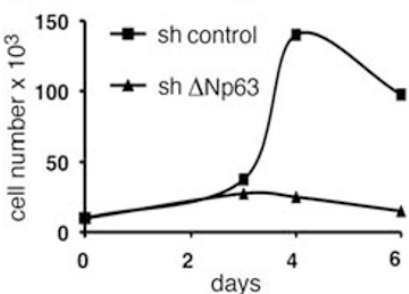

c

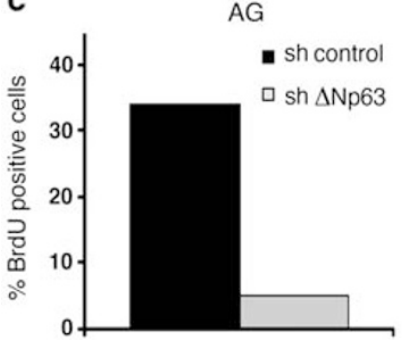

$\operatorname{sh} \triangle \operatorname{Np} 63$

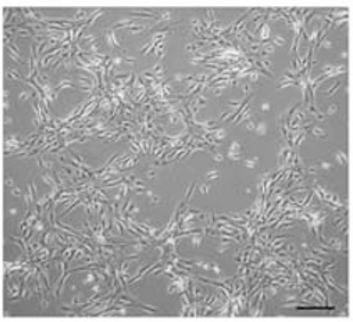

AP

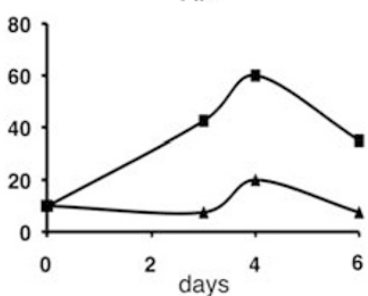

AP

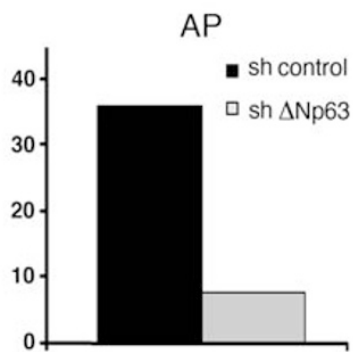

d
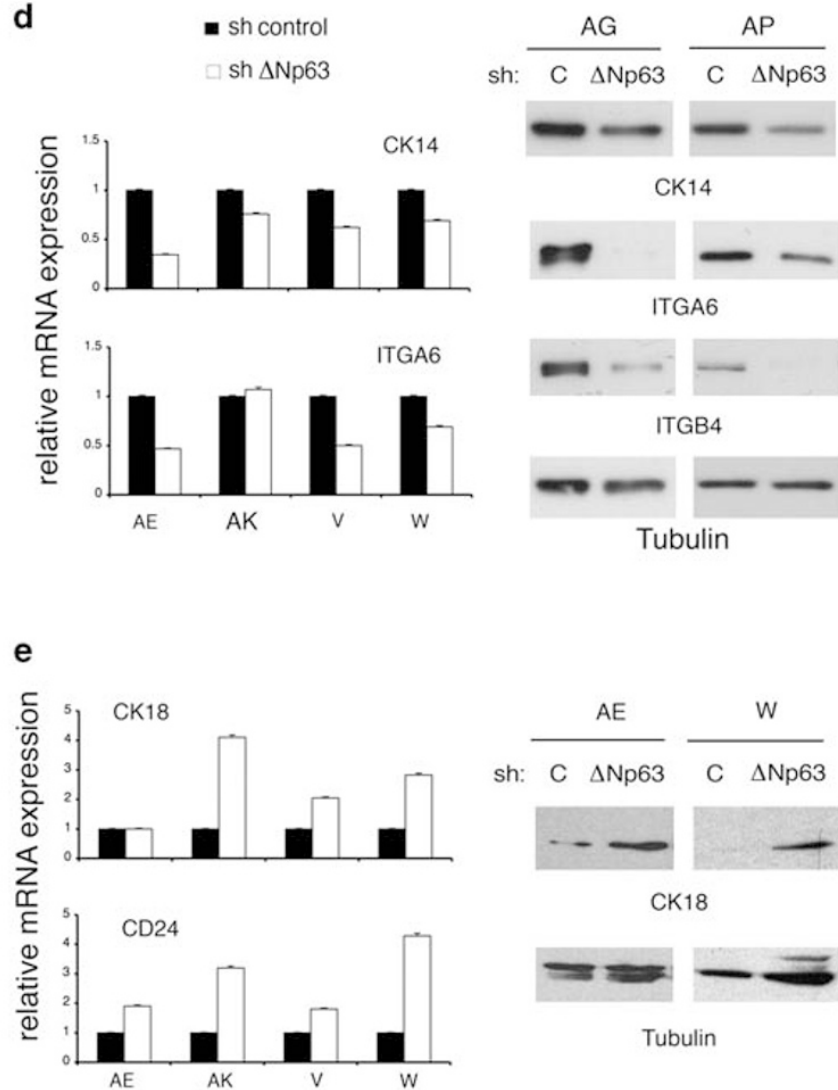

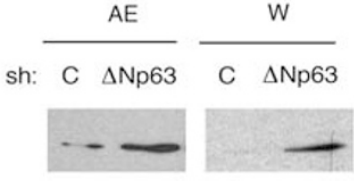

CK18

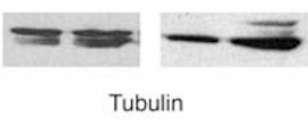

Figure 1 Silencing $\triangle$ Np63 expression in CD10 $(+)$-sorted HBECs induces luminal characteristics. (a) Photomicrographs of CD10 $(+)$-sorted HBECs $72 \mathrm{~h}$ after infection with control or $\triangle \mathrm{Np} 63$ shRNA-expressing lentiviruses. Note lower cell density in $\triangle \mathrm{Np} 63$ versus control shRNA-infected cell populations. Scale bar: $0.2 \mathrm{~mm}$. (b) Growth curves of HBECs from two different patients plated at equal numbers on day 0 , at $72 \mathrm{~h}$ after infection with control (squares) or $\triangle \mathrm{Np} 63 \mathrm{shRNA}$-expressing (triangle) lentivirus. (c) Bar graphs representing percentage of BrdU-positive cells in control (34.1 and 35.7\%) and $\Delta$ Np63 shRNA-expressing (4.9 and 7.8\%) CD10(+)-sorted HBECs on day 8 after infection. (d, e) Expression levels of basal (d) and luminal (e) markers at mRNA and protein levels. Relative mRNA expression levels of basal markers CK14 and ITGA6 (d) and luminal markers CK18 and CD24 (e) in HBECs from four different individuals after infection with control (filled bars) or $\triangle$ Np63 shRNA (open bars)-expressing virus. mRNA values represent the mean \pm S.D. of three replicate samples, normalized to TATA box-binding protein (TBP). (AE: 4, AK: $8, V: 5$, W: 3 days after infection) (P-values: CK14, 0.09; ITGA6, 0.12; CK18, 0.12; and CD24, 0.03). Western blot of HBECs day 5 after infection with control shRNA (C) or $\triangle$ Np63 shRNA-expressing lentivirus 

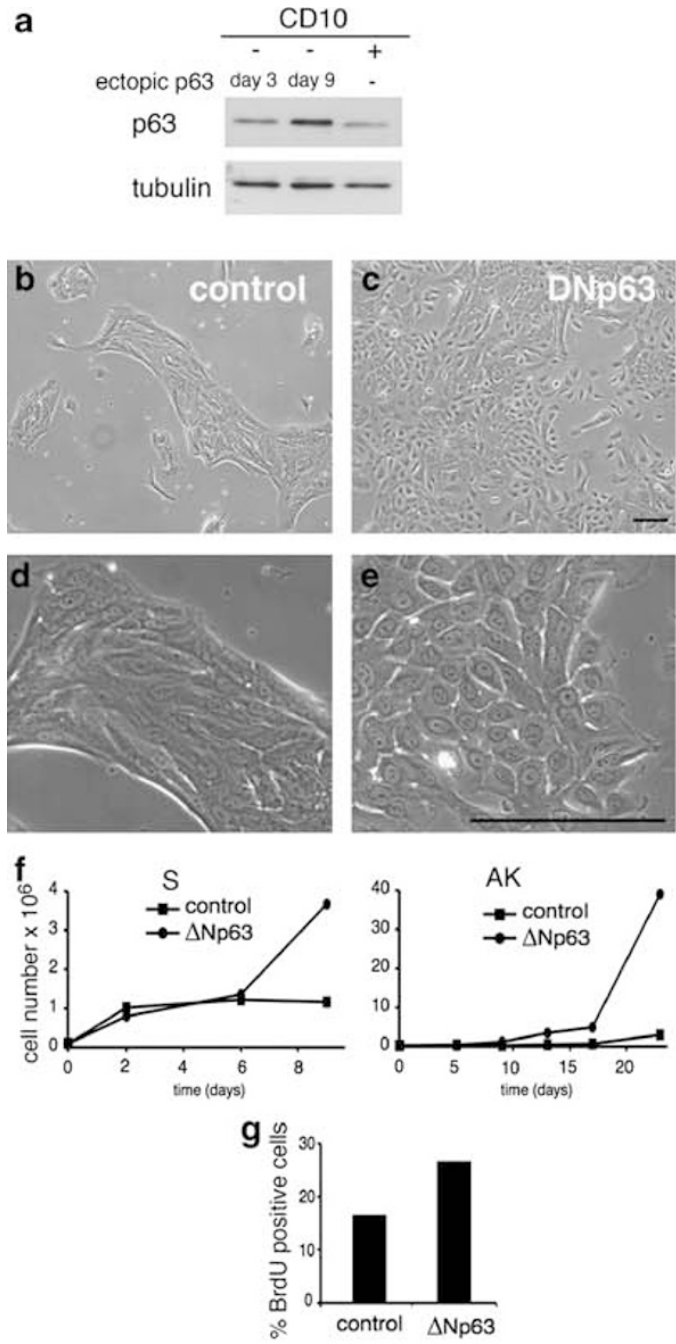

h
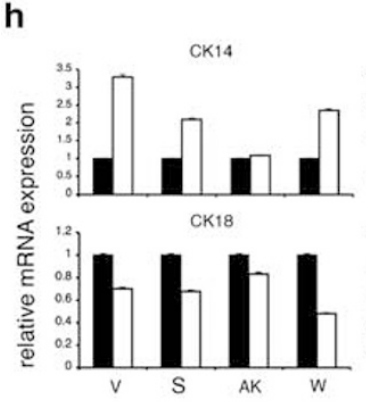

i

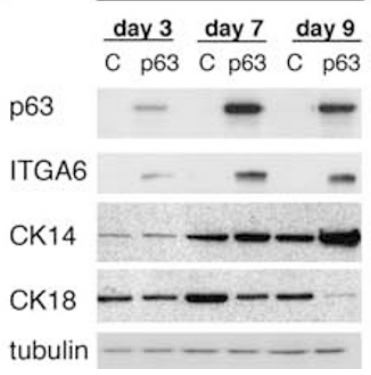

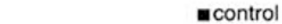
$\triangle \mathrm{Np63}$
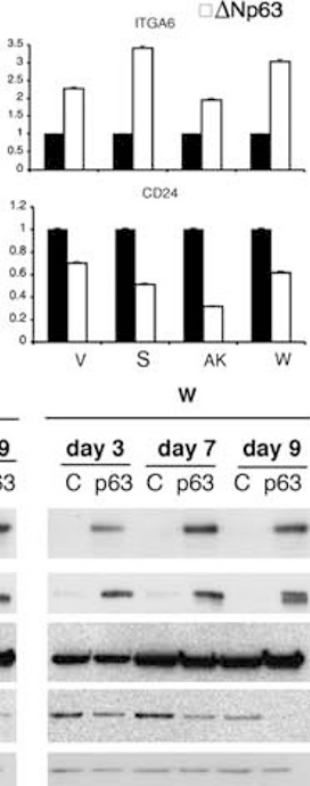

that $\Delta \mathrm{Np63}$ is essential for the maintenance of basal cell fate and is negatively regulated by Notch signaling. We provide evidence that this antagonism operates in vivo during pubertal ductal morphogenesis in the mouse mammary gland.

\section{Results}

$\Delta$ Np63 function in maintaining basal versus luminal cell fates. To assess the role of p63 expression in basal breast epithelial cells, we performed loss- and gain-of-function experiments with primary HBECs. We purified luminal and basal cell populations from reduction mammoplasties using magnetic beads and an antibody recognizing CD10; ${ }^{1}$ cell separation was validated by assessing marker gene expression (Supplementary Figure 1a). As reported by O'Hare et al., ${ }^{26}$ the two populations had distinct phenotypes: $\mathrm{CD10}(+)$ basal HBECs proliferated faster than CD10 $(-)$ luminal cultures and propagated over eight passages. $\mathrm{CD} 10(+)$ cells were refractile and tended to scatter (Supplementary Figure 1b). CD10(-) HBECs formed sheets with indistinct cell boundaries (Supplementary Figure 1b) and grew only up to 2-4 passages. Both cultures remained homogeneous over time and continued to express respective markers (Supplementary Figure 1c).

Having ascertained that $\Delta N p 63 \alpha$ is the predominant p63 isoform expressed in HBECs (Supplementary Figure 2a-d), we downmodulated $\Delta \mathrm{Np63}$ expression in CD10 $(+)$ cells by shRNA-mediated knockdown (Supplementary Figure 2c and d). $\Delta$ Np63 shRNA-expressing cultures grew less dense (Figure 1a) and increased less in cell numbers (Figure 1b) than control-infected populations. Consistent with $\Delta \mathrm{Np} 63$ downmodulation resulting in decreased proliferation, bromodeoxyuridine (BrdU) was incorporated by 34.1 and $35.7 \%$ of the control-infected cells and only by 4.9 and $7.8 \%$ of $\Delta \mathrm{Np} 63$ shRNA-expressing cells (Figure 1c). Transcript levels of basal markers such as CK14 and ITGA6 decreased (Figure 1d), whereas those of the luminal markers, $C D 24$ and $C K 18$, increased on $\triangle N p 63$ depletion (Figure 1e). Similarly, ITGA6, ITGB4, and CK14 decreased (Figure 1d) and CK18 (Figure 1e) increased at the protein level. These results

Figure $2 \Delta$ Np63 expression in CD10(-)-sorted HBECs induces basal characteristics. (a) p63 protein levels in $\mathrm{CD} 10(-)$ cells on days 3 and 9 after infection with $\triangle$ Np63-expressing retrovirus compared with endogenous $p 63$ levels in $\mathrm{CD} 10(+)$ HBECs 3 days after control infection. (b-e) Photomicrographs of CD10(-)-sorted HBECs 13 days after infection with control or $\triangle$ Np63-expressing virus. CD10(-)-sorted HBECs form islands (b) consisting of flat cells with indistinct cell borders characteristic of luminal cells (d). $\Delta$ Np63-infected populations show higher cell density and contain refractile, spindle-shaped cells (c, e). Scale bar: $0.2 \mathrm{~mm}$. (f) Growth curves of HBECs infected with control (squares) or $\triangle \mathrm{Np} 63$ (circles)-expressing virus. (g) Percentage of BrdU-positive cells among GFP$\triangle$ Np63- $(26.7 \%)$ and GFP only (16.6\%)-expressing cells at day 8 after infection. (h) Relative mRNA levels of luminal (CK18, CD24) and basal (CK14, ITGA6) markers in CD10(-) HBECs from four different donors infected with control (filled bars) or $\Delta \mathrm{Np} 63$ (open bars)-expressing virus (V, 2; $\mathrm{S}$ and $\mathrm{AK}, 7$; and $\mathrm{W}, 10$ days after infection). Values represent the mean \pm S.D. of three replicate samples normalized to TBP ( $P$-values: CK14 <0.23; CK18 <0.05; ITGA6 <0.07; and CD24 <0.02). (i) p63, ITGA6, CK14 and CK18 protein levels in CD10(-)-sorted HBECs from two different donors at different days after infection with either control (C) or $\Delta$ Np63 (p63) expressing virus 
suggested that $\Delta N p 63$ expression is required to maintain the basal versus the luminal phenotype in HBECs.

To address whether $\triangle N p 63$ is sufficient to induce a basal conversion, we ectopically expressed $\Delta \mathrm{Np} 63$ in $\mathrm{CD} 10(-)$ luminal cells. Western blotting revealed that ectopically expressed p63 in CD10(-) HBECs reached levels comparable with those of endogenous p63 in CD10 $(+)$ cells 3 days after infection (Figure 2a). As expected, control-infected luminal cell populations grew slowly as islands (Figure $2 b$ ) and had indistinct cell borders (Figure 2d). By contrast, in $\Delta$ Np63-expressing populations, cells became refractile and scattered similar to basal cells (Figure $2 \mathrm{c}$ and e). ${ }^{26}$ Cell numbers increased by about fourfold at 9 days and by 40 -fold at 23 days after infection over their respective controls (Figure 2f). The percentage of cells in $\mathrm{S}$ phase increased, with $26.7 \%$ of GFP- $\Delta$ Np63- versus $16.6 \%$ of GFP-onlyexpressing cells incorporating BrdU (Figure $2 \mathrm{~g}$ ). The morphological changes were accompanied at the molecular level by increased CK14 and ITGA6 and decreased CK18 and CD24 mRNA expression (Figure $2 \mathrm{~h}$ ). At the protein level, ITGA6 and CK14 were increased and CK18 decreased in cultures expressing $\Delta \mathrm{Np} 63$ (Figure 2i). Thus, expression of $\Delta \mathrm{Np63}$ is sufficient to induce several hallmarks of the basal phenotype in CD10(-)-sorted HBECs.

The role of Notch in driving luminal cell fate depends on negative regulation of $\Delta \mathrm{Np63}$. Our findings suggested that $\Delta \mathrm{Np63}$ is an essential control element in the maintenance of basal versus luminal cell fates. Notch3 and Notch1 have recently been implicated in driving luminal cell fate. ${ }^{10,12}$ In keratinocytes, Notch1 signaling promotes differentiation and negatively regulates p63 expression, ${ }^{27,28}$ making Notch signaling an attractive pathway upstream of $\Delta \mathrm{Np} 63$ to investigate. To test whether Notch drives luminal cell commitment by downmodulating $\Delta \mathrm{Np63}$, we expressed the intracellular domain of Notch1 (NICD) in primary HBECs. Within $48 \mathrm{~h}$ of infection, $\triangle N p 63$ transcript was significantly decreased (Figure $3 \mathrm{a}$ ) and $\Delta \mathrm{Np} 63$ protein was consistently reduced (Figure $3 \mathrm{~b}$ ). NICD-expressing HBECs aggregated and could not be passaged. To assess the effects of Notch activation on cell proliferation, we expressed NICD under the control of phosphoglycerate kinase (PGK) promoter. This approach yielded lower NICD expression levels and less Notch signaling activation, as assessed by target gene expression (Supplementary Figure 3a), and allowed us to passage the NICD-expressing HBECs. Cell density was reduced by both high and low NICD expression (Figure $3 \mathrm{c}$ ). Increase in cell number assessed in low NICD-expressing HBECs was reduced (Figure $3 d$ ). Consistent with this being due to decreased proliferation, BrdU incorporation (Figure 3e) and Ki67 labeling (Figure 3f) were lower among cells expressing NICD and GFP than GFP-only-expressing cells. Furthermore, increased Notch activity resulted in significant downmodulation of integrins enriched in basal cells, such as ITGB1, ITGB4, and ITGA6 (Figure $3 g$ and $h$ ), similar to what was observed in MCF10A cells depleted for $\triangle \mathrm{Np} 63^{25}$ As we failed to detect increased expression of the luminal marker CK18 in HBECs with constitutive Notch activation, we expressed a NICD fused to a mutant ER $\alpha$ that can be transiently activated by exposure to $4-\mathrm{OH}$ - tamoxifen. ${ }^{29}$ Treatment of HBECs expressing this construct with $4-\mathrm{OH}$-tamoxifen for $8 \mathrm{~h}$ resulted in increased Notch signaling activity, as assessed by increased mRNA expression of Hey-1 (Supplementary Figure 3b) and increased CK18 mRNA expression by 3.4-fold over 14 days (Figure 3i). Thus, activation of Notch signaling not only downmodulates $\Delta \mathrm{Np63}$ expression but also has effects on cell proliferation and marker gene expression similar to those caused by $\Delta$ Np63 depletion.

To address the functional significance of $\Delta N p 63$ downmodulation in the context of increased Notch signaling, we coinfected unsorted HBECs with NICD and $\triangle$ Np63-expressing retroviruses. As expected, in NICD-expressing cultures, cells aggregated and cell density was reduced compared with control cultures (Figure $4 \mathrm{a}$ and $\mathrm{b}$, left versus middle panels). In the cultures coexpressing NICD and $\triangle \mathrm{Np} 63$, cell density was comparable with control populations (Figure $4 a$ and b, right panels). Increased $\Delta$ Np63 expression also counteracted Notch-induced downmodulation of ITGB1, ITGB4, and ITGA6 at the mRNA level (Figure 4c). At the protein level, Notchinduced downmodulation of ITGB4 was counteracted by ectopic $\Delta$ Np63 expression (Figure $4 \mathrm{~d}$ ). Thus, $\Delta$ Np63 downmodulation is required for, at least, some of the effects of Notch in HBECs.

$\Delta$ Np63/Notch signaling in vivo. Our findings indicated that persistent expression of $\Delta \mathrm{Np} 63$ is required to maintain basal cell fate in HBECs by counteracting the role of Notch in driving and/or maintaining luminal cell fate. Such an antagonism between Notch signaling and p63 expression had been suggested to be of importance to maintain luminal cells, specifically during pregnancy, in the mouse mammary gland. ${ }^{30}$ To assess when and where canonical Notch signaling is active during mammary gland development, we used a transgenic Notch reporter (TNR) mouse strain, which includes an EGFP gene downstream of CBF1/RBP-J $\kappa_{-}$ responsive element (four CBF1-binding sites and the basal simian virus 40 promoter). GFP expression was shown to faithfully reflect $\mathrm{CBF} 1$ activity. ${ }^{31}$ By fluorescent stereomicroscopy, GFP was first detected in mammary glands at 3 weeks of age, at the onset of puberty; the signal peaked between 4 and 6 weeks, it was weak at 12 weeks, and undetectable thereafter (Figure 5a). Thus, canonical Notch activity, as detected by this approach, was specific to pubertal ductal morphogenesis. At this stage of mammary gland development, extensive cell proliferation occurs at the tips of the ducts, which enlarge to become terminal end buds (TEBs). ${ }^{32}$ TEBs comprise an outer layer of cap cells, enriched in stem and myoepithelial progenitor cells and inner body cells considered as luminal precursor cells. ${ }^{32,33}$ Consistent with an involvement of Notch signaling in cell fate determination, the GFP signal was strongest at TEBs and decreased proximally along the subtending ducts (Figure 5b-d). Coimmunostaining for GFP and p63 revealed that expression of the two was mutually exclusive; p63 was expressed in cap or myoepithelial cells, whereas GFP expression was detected in body cells (Figure 5e, left panel) and luminal cells of the subtending duct (Figure $5 e$, right panel). 
According to our model, Notch signaling is initially activated in basal/progenitor cells, in which it leads to downmodulation of p63 expression and triggers luminal differentiation. Hence, a subpopulation of $C D 24^{l o}$ cells was expected to have active Notch signaling and decreased expression levels of p63. Low GFP expression and subtle differences in p63 expression might not be discerned by immunohistochemical approach used in the previous experiment. Hence, we FACSsorted MMECs from 4 to 5-week-old reporter mice on the basis of GFP and CD24 expression after exclusion of stromal a

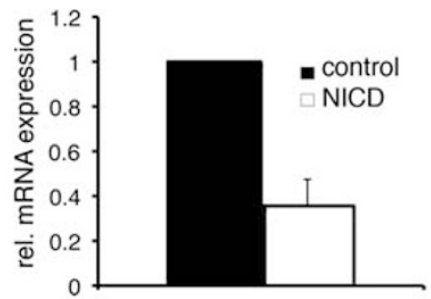

b

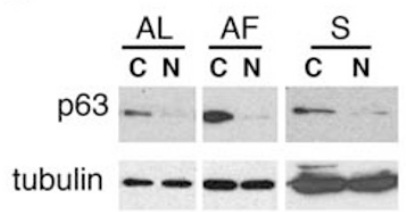

c C AK

$\mathrm{Hi}$

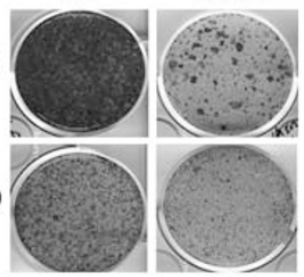

C

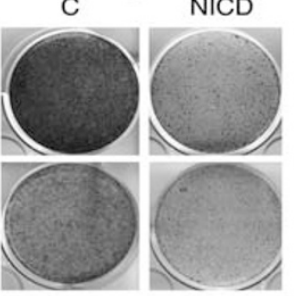

C $A$

$\mathrm{AD}_{\text {NICD }}$
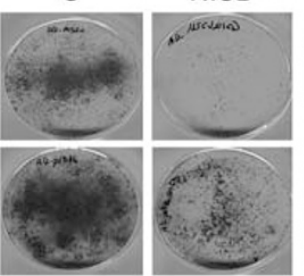

AL

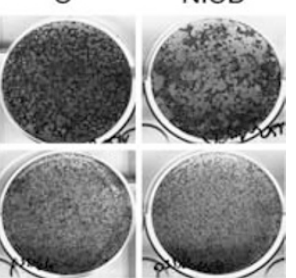

d
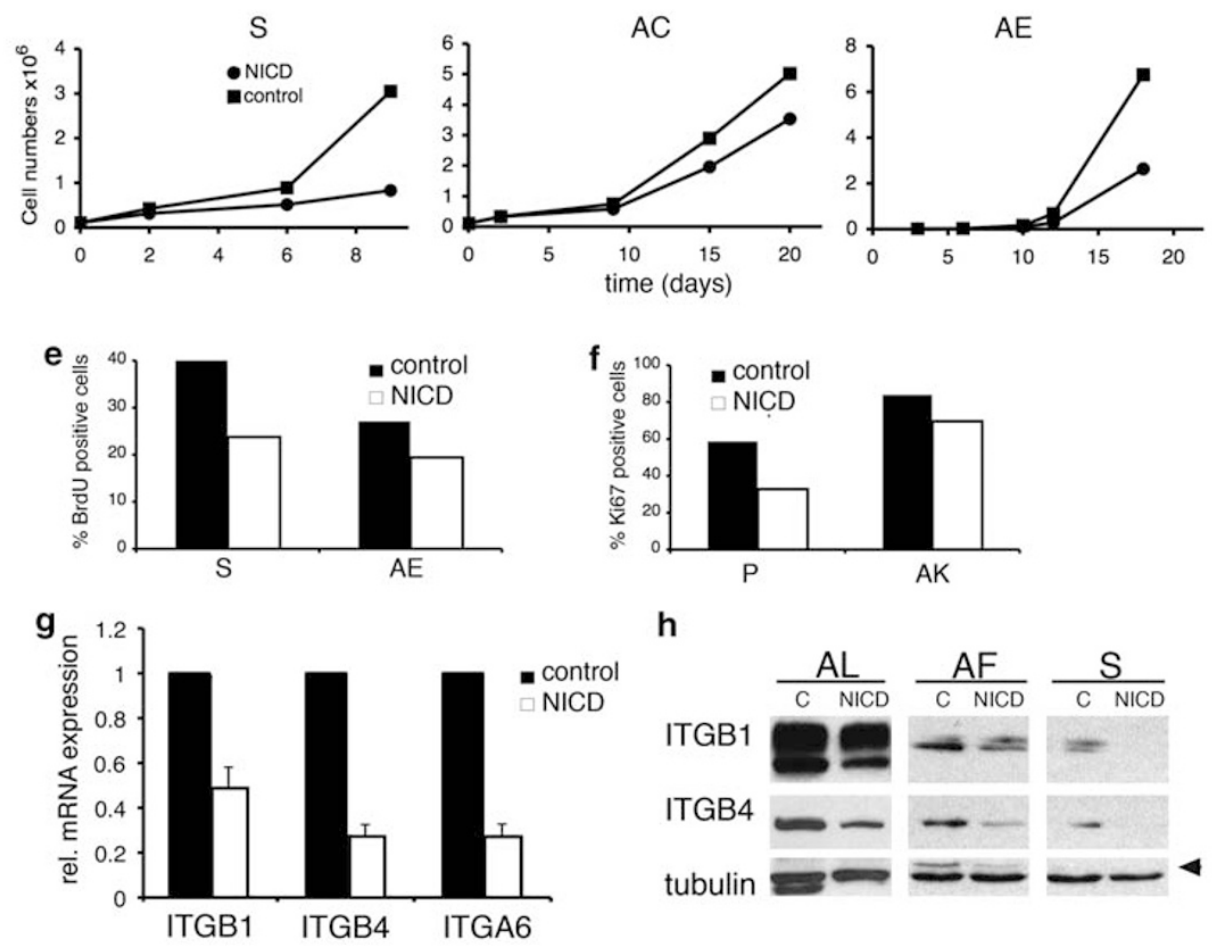

h
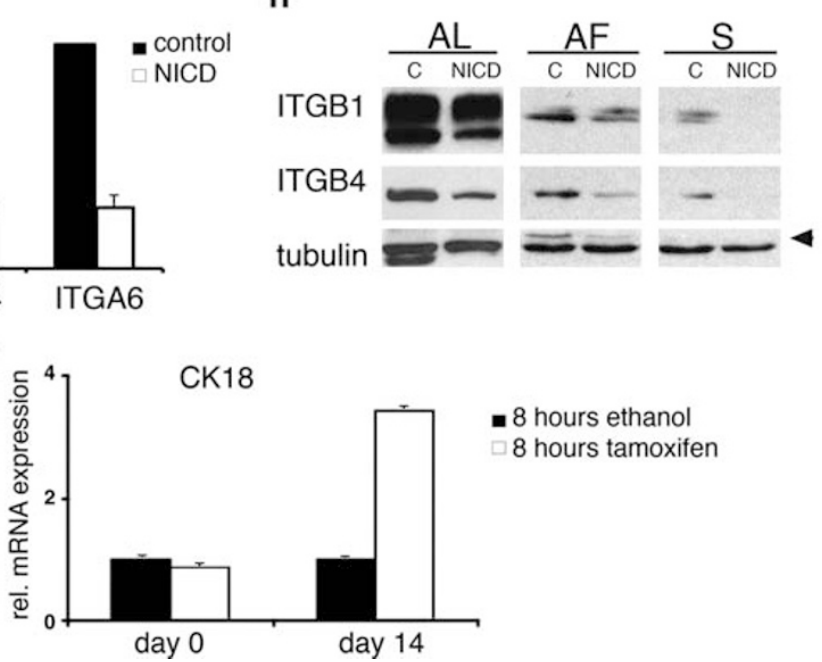

8 hours ethanol

8 hours tamoxifen 
cells. Both $C D 24^{l o}$ and $C D 24^{h i}$ populations comprised of GFP-positive cells (Figure 5f). Consistent with the immunofluorescence results, $C D 24^{\text {hi }}$ cells expressed higher levels of GFP both at the protein (Figure $5 f$ ) and mRNA levels (Figure $5 \mathrm{~g}$ ) than $\mathrm{CD} 24^{l o}$ cell populations. Furthermore, gene expression analysis showed that ITGB1 and ITGA6 were enriched in $C D 24^{l o}$ versus $C D 24^{h i}$ cells and that p63 itself was expressed at about 170 -fold higher levels in $C D 24^{l o}$ than in $C D 24^{h i}$ MMECs (Figure $5 \mathrm{~g}$ ), validating the cell separation procedure. Strikingly, among the $C D 24^{l o}$ cells, the GFPpositive population showed consistently reduced p63 mRNA expression (Figure $5 \mathrm{~g}$ ). Thus, in $C D 24^{10} \mathrm{MMECs}$, in which Notch signaling is or has been active, p63 mRNA expression levels are decreased, consistent with Notch activation, decreasing p63 expression in progenitor cells in vivo.

Requirement of $\Delta \mathrm{Np63}$ downmodulation and activation of Notch signaling in vivo. To address whether downmodulation of $\Delta \mathrm{Np} 63$ is required to establish luminal cells in vivo, we resorted to mammary gland reconstitution experiments. Briefly, in 3-week-old mice, the inguinal mammary glands can be cleared of endogenous epithelium by surgically removing the nipple-near half that contains the rudimentary ductal system. The MMECs that are injected into the remaining 'cleared' fat pad will give rise to a new ductal system. ${ }^{34}$ Primary MMECs infected with either GFP- $\triangle$ Np63 or a GFP control virus, were injected into contra lateralcleared mammary fat pads. After 3 months, MMECs infected with GFP virus gave rise to ductal systems with widespread GFP expression (Figure 6a, b, and d), whereas GFP- $\Delta$ Np63 virus-infected MMECs reconstituted less overall (Figure 6a) and had spotty GFP expression (Figure $6 \mathrm{c}$ and e). To determine the specific cell fate of the infected cells, we performed immunohistochemistry for the myoepithelial cell marker, smooth muscle actin (SMA). Coimmunostaining revealed that GFP control MMECs were present in both cell compartments with $66 \%$ being $\mathrm{SMA}(-)$ and being $34 \%$ $\mathrm{SMA}(+)$ (Figure $6 \mathrm{f}$ and $\mathrm{g}$ ). Among the $\triangle$ Np63-GFP-infected cells, only $14 \%$ were SMA $(-)$ but $86 \%$ were $\operatorname{SMA}(+)$ (Figure $6 \mathrm{~h}$ and i). Thus, constitutive $\Delta \mathrm{Np} 63$ expression impairs overall reconstitution and specifically inhibits luminal cell fate, indicating that downmodulation of $\Delta \mathrm{Np} 63$ is required to establish and/or maintain luminal cell lineage in vivo.

To address whether Notch activation is functionally important for the control of $\Delta \mathrm{Np} 63$ expression in vivo, we deleted both alleles of the central Notch mediator CBF1/RBP$J_{\kappa}$ in the mammary epithelium. Mice in which both alleles of
RBP-J $\kappa$ were flanked by loxP sites $\left(R b p s u h^{f / / f}\right)$ were crossed with MMTV-Cre transgenic mice. ${ }^{30}$ Analysis of mammary glands from 5-week-old mice by whole mount microscopy revealed no obvious difference (Figure $7 a$ and $b$ ), which is consistent with previous work. ${ }^{30}$ However, as the MMTV-LTR is only active in a subset of MMECs, it was conceivable that CBF1/RBP-J $J_{\kappa}$-deficient MMECs were outgrown by undeleted, wild-type (WT) MMECs. To address this concern, we crossed the mice with a Cre reporter strain designated Z/EG (LacZ/EGFP), ${ }^{35}$ in which Cre excision activates expression of EGFP. Mammary epithelium of MMTV-Cre.Z/EG double transgenic mice, with one WT allele of $R B P-J \kappa$, showed a strong GFP signal (Figure 7d and f). Immunostaining revealed that about $20 \%$ of the MMECs express GFP (Figure $7 \mathrm{~h}$ and I). In contrast, in MMTV-Cre.Z/EG double transgenic mice homozygous for the conditional $R B P-J \kappa$ allele, GFP signal was scarce (Figure 7c and e) and few GFP-expressing cells were detected by immunostaining (Figure $7 \mathrm{~g}$ and $\mathrm{k}$ ), indicating that RBP-J $\mathrm{J}_{\kappa}$-deficient cells were negatively selected. Interestingly, coimmunostaining for GFP and p63 revealed that in RBPfl/WT double transgenic epithelia, GFP $(+)$ cells were present in both $p 63(+)$ and p63(-) compartments (Figure 7h, j and I), whereas in RBPfl/fl double transgenic epithelia all the $\operatorname{GFP}(+) / \mathrm{RBP}-\mathrm{J}_{\kappa}$-deficient MECs expressed p63 (Figure 7g, i and k) and SMA (Supplementary Figure 4). This indicates that RBP-J $\kappa$-deficient cells were unable to downmodulate p63 expression and did not contribute to the luminal layer. Thus, both activation of canonical Notch signaling and downmodulation of $\Delta \mathrm{Np} 63$ are required to establish and/or maintain luminal cells in vivo.

\section{Discussion}

In the present paper, we provide, to our knowledge, the first evidence for a role of $\Delta \mathrm{Np} 63$ in controlling cell fate in the breast epithelium, both in primary HBECs in vitro and in the mouse mammary gland in vivo. We show that $\Delta \mathrm{Np} 63$ is a determinant of basal/myoepithelial cell type under negative Notch control. Our results regarding the Notch function in this context are in line with studies that implicated Notch signaling in restricting bipotential progenitors to a luminal cell fate. ${ }^{10,12}$ They extend them by providing evidence for a functional requirement of canonical Notch signaling in establishing the luminal cell lineage in vivo and identifying suppression of $\Delta$ Np63 expression as an important underlying mechanism.

Our findings are consistent with a model for the establishment of breast epithelial cell fates through antagonistic

Figure 3 Activation of Notch signaling in HBECs. (a) QRT-PCR analysis of $\triangle N p 63$ mRNA levels normalized to TBP in HBECs from eight different donors infected with control (filled bar) or NICD (open bar)-expressing retrovirus. (b) Immunoblot of p63 protein in HBEC lysates from three different donors infected with control (C) or NICD (N) retrovirus. (c) Crystal violet staining of HBECs from four different donors 20-26 days after infection with control (C) or NICD-expressing virus, top: high NICD (Hi) expression by retrovirus, bottom: low NICD expression by lentivirus (Lo). (d) Growth curves of HBECs from three different donors infected with control (squares) or NICD-expressing (circles) lentivirus. (e) Percentage of BrdU-positive cells in control (filled bars) (40.7 and 27.1\%) and NICD-expressing (open bars) (23.8 and 19.4\%) HBECs on days 6 (patient S) and 11 (patient AE) after infection. (f) Percentage of Ki67-positive cells in control (filled bars) (58.8 and 83.9\%) and NICD-expressing (open bars) (32.7 and $69.6 \%$ ) HBECs on days 6 (patient P) and 8 (patient AK) after lentiviral infection. (g) QRT-PCR analysis of ITGB1, ITGB4, and ITGA6 mRNA levels normalized to TBP in HBECs from eight different donors infected with control (filled bar) or NICD (open bar)-expressing retrovirus ( $P$-values: ITGB1 $<7.4 \times 10^{-5}$; ITGB4 $<2.5 \times 10^{-7}$; ITGA6 $<2.5 \times 10^{-7}$ ). (h) ITGB1 and ITGB4 protein expression in HBECs from three different donors infected with control (C) or NICD-expressing retrovirus. (i) QRT-PCR analysis of CK18 mRNA expression in HBECs infected with inducible NICD virus. At 7 days after infection, cells were treated with ethanol (black bars) or 4-OH-tamoxifen (open bars) for $8 \mathrm{~h}$ and analyzed either directly after treatment (day 0 ) or 14 days later 


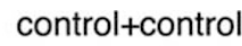

$\mathrm{AH}$

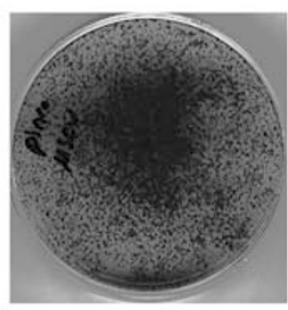

b

$\mathrm{S}$
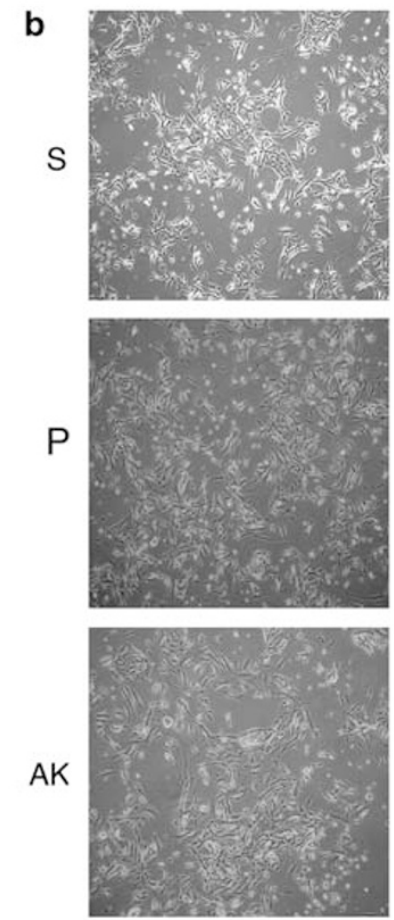

control+NICD
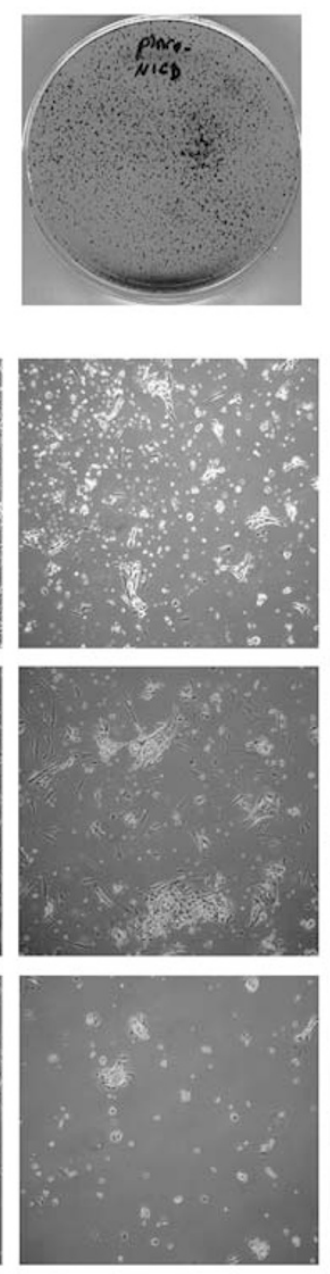

$\triangle \mathrm{Np63+NICD}$
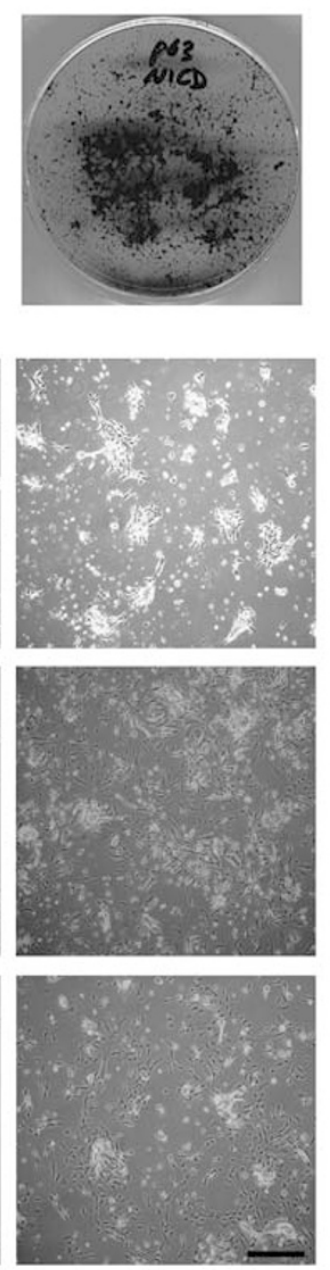

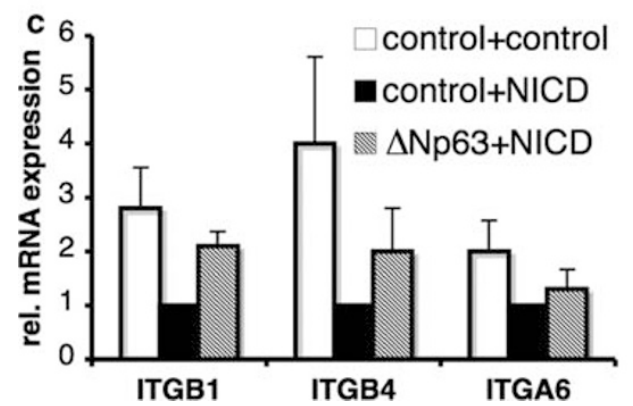

d
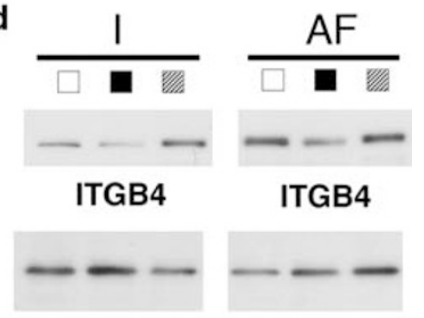

tubulin

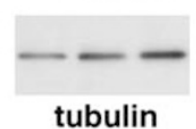

Figure $4 \Delta$ Np63 partially inhibits NICD effect in HBECs. (a) Crystal violet staining of HBECs double infected with two control viruses, control and NICD, or with $\triangle N p 63$ and NICD viruses. (b) Photomicrographs of HBECs from three different donors double infected in this way. Note, that cell densities reduced and cells formed clusters in NICDexpressing populations (middle panels). $\triangle \mathrm{Np63}$ and NICD coexpressing cell populations (right panels) show similar density to control (left panels) and cluster less than NICDonly-infected cells. Scale bar: $0.05 \mathrm{~mm}$. (c) QRT-PCR analysis of relative mRNA expression of ITGB1, ITGB4, and ITGA6 after infection with two control (open bars), control and NICD (black bars), and $\triangle \mathrm{Np} 63$ and NICD (gray bars) retroviruses. Three replicate samples were analyzed and normalized to TBP. Values represent the mean \pm S.D. of three independent experiments with HBECs from distinct donors. Note, $\triangle$ Np63 expression partially overcomes NICD-induced reduction of integrin mRNA expression ( $P$-values: ITGB1, 0.02; ITGB4, 0.16; and ITGA6, 0.29). (d) ITGB4 protein levels in HBECs from different patients 9 days after infection with two control (open square), control and NICD (black square) and $\triangle N p 63$ and NICD (gray square) retroviruses

interaction of $\Delta \mathrm{Np} 63$ and Notch (Figure 8). The striking global changes observed with cultured HBECs suggest that myoepithelial and luminal cells are interconvertible, controlled by the relative balance of $\Delta \mathrm{Np} 63$ and Notch expression and activity (Figure 8, dashed arrows). Alternatively, they may reflect increased plasticity of HBECs in vitro ${ }^{36}$ with a large population of $\Delta \mathrm{Np} 63(+)$ progenitor-like cells ${ }^{37}$ that would be the prime target for $\Delta \mathrm{Np63/Notch}$ interplay leading to 
a
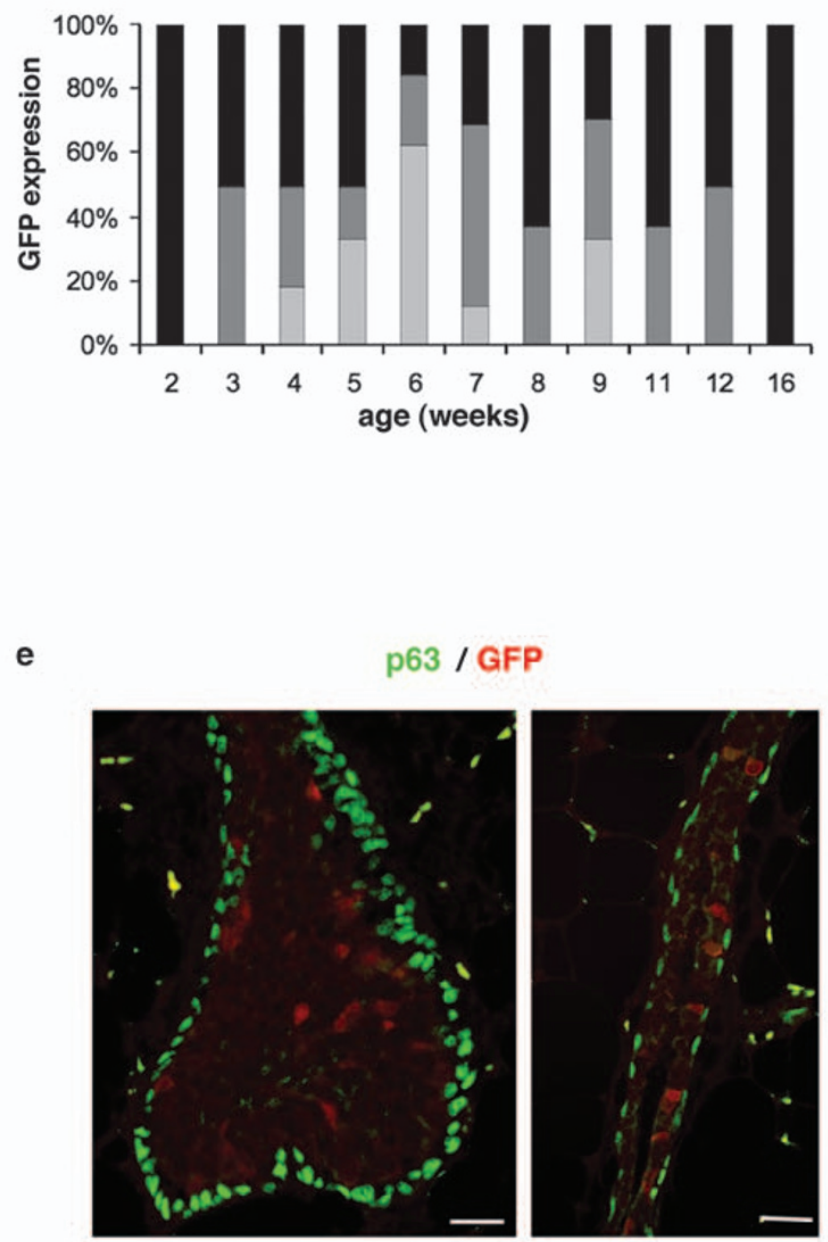
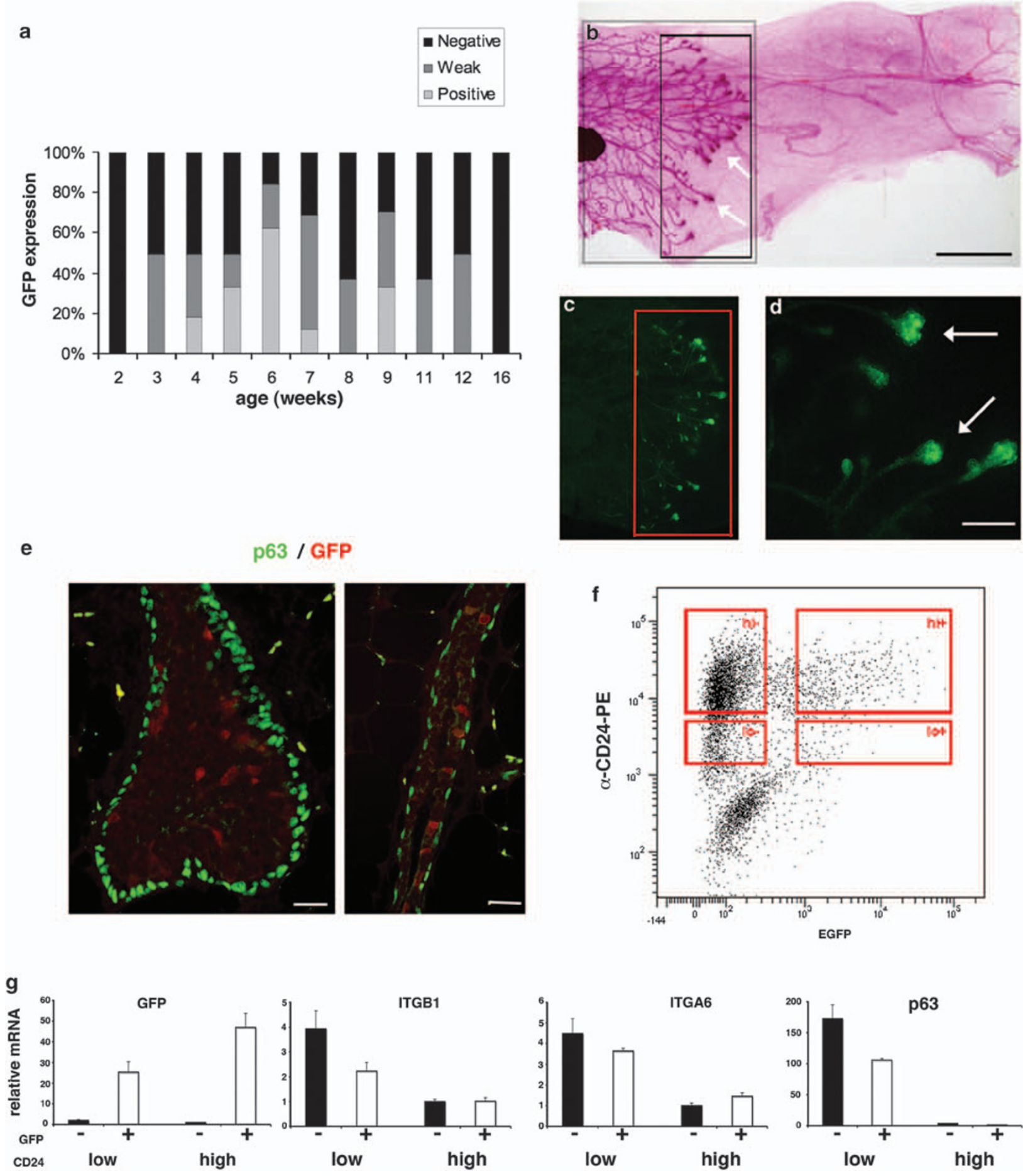

Figure 5 Notch signaling is activated during ductal outgrowth and reduces p63 expression levels in vivo. (a) Mammary glands of TNR mice ( $n=4-6$ per age value) analyzed at different developmental stages were scored for overall GFP signal intensity as negative, weak, or positive. The percentage of each category was plotted over the age of the mice. Strong activation of Notch signaling was specifically observed between 4 and 6 weeks of age. (b) Stereomicrograph of a whole-mounted mammary gland from a 5-week-old TNR female. Black box represents the growing end of the mammary gland with TEBs indicated by arrows. Scale bar: $1 \mathrm{~mm}$. (c) Fluorescence image of the area indicated by gray box in $\mathbf{b}$. Note that GFP expression reflecting Notch activity is detected at the growing front of the ductal system marked by red box, which corresponds to the black box in b. (d) Higher magnification of TEBs (arrows) shown in c. Scale bar: $100 \mu \mathrm{m}$ (e) Coimmunofluorescence for GFP (red) and p63 (green) on a mammary gland section from a 6-week-old TNR transgenic female; TEB (left panel) and subtending ducts (right panel). Note, Notch activity detected by GFP expression (red), is found exclusively in the body cells of TEB and luminal cells of immediately subtending duct; it is mutually exclusive with p63 expression. Scale bar: $30 \mu \mathrm{m}$. (f) Representative FACS dot plot showing the distribution of TNR MECs based on CD24 and GFP expression. Boxes outline the sorted populations. (g) Representative QRT-PCR analysis of the four distinct FACS-sorted MMEC populations. Three replicate samples were analyzed and normalized to $36 \mathrm{~B} 4$. Note, p63 expression is specific to the CD24 $4^{10}$ population. Within the $\mathrm{CD} 24^{10}$ population, p63 expression is lower in the GFP $(+)$ than in $\operatorname{GPF}(-)$ subpopulations $(P$-values of four independent experiments is 0.07$)$ 


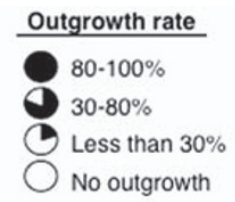

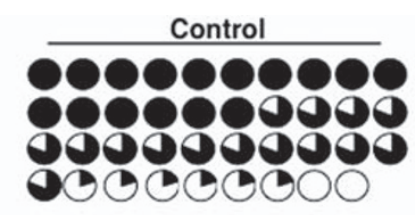

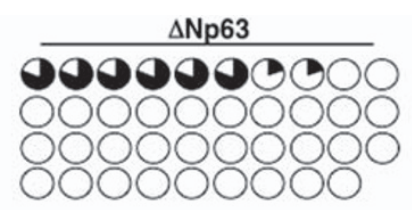

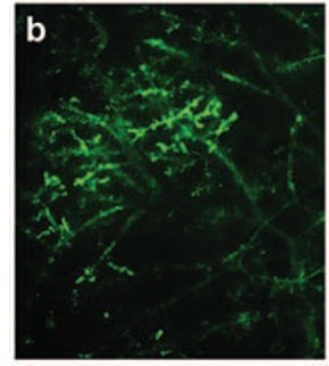

SMA
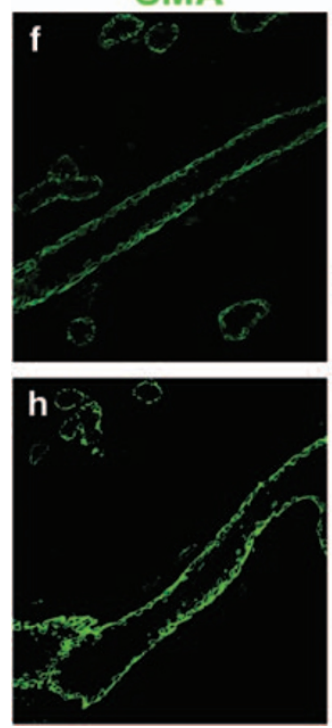

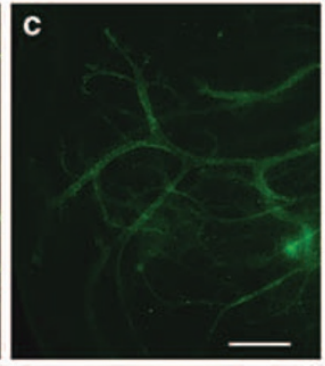

GFP
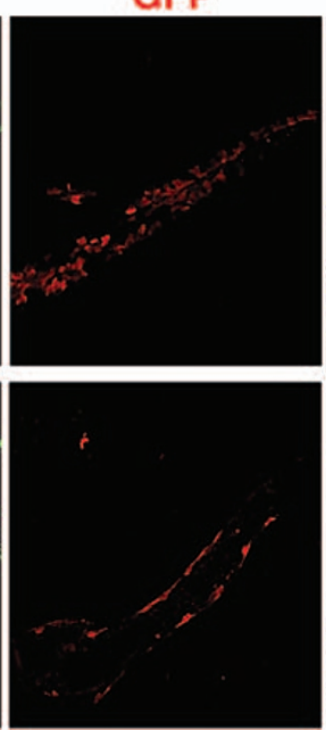
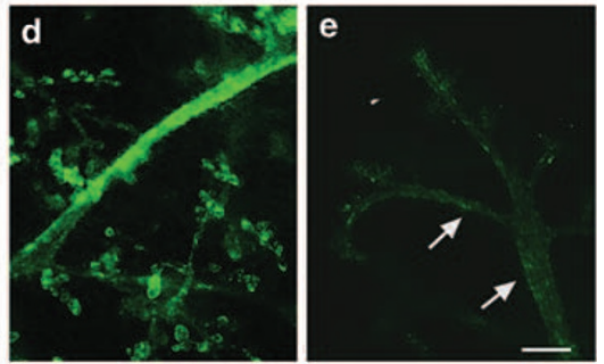

SMA/GFP/DAPI
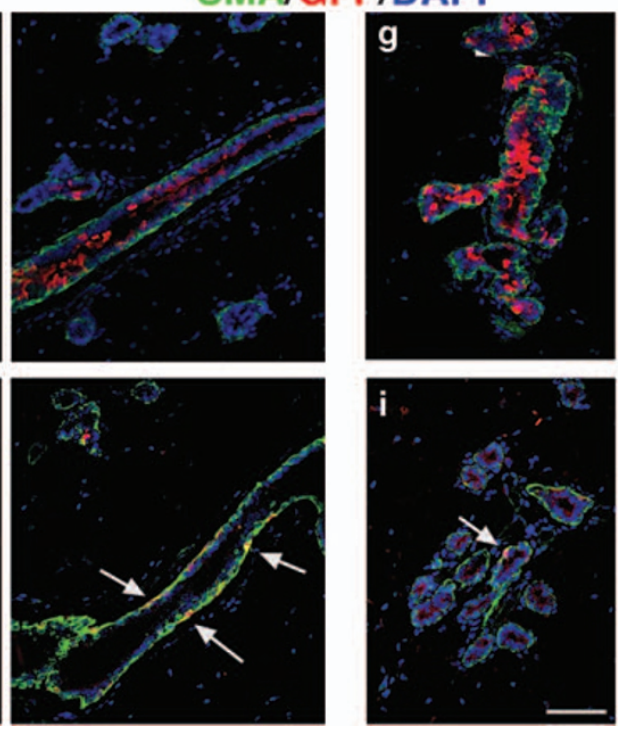

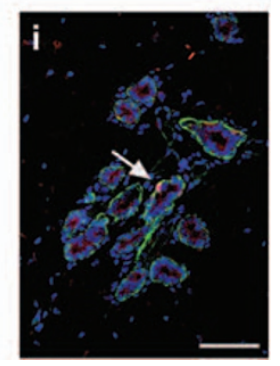

Figure 6 Constitutive $\triangle$ Np63 expression is incompatible with luminal cell fate. (a) Mammary gland reconstitution with MMECs infected with GFP only (control) or GFP$\Delta \mathrm{Np63}$ ( $\Delta \mathrm{Np63)}$-expressing viruses. Each circle represents one mammary gland; the blackened region represents the area filled with outgrowth (b-e). Fluorescence images show outgrowths of mammary glands reconstituted with control (b and $\mathbf{d}$ ) or $\triangle$ Np63-expressing MMECs (c and $\mathbf{e}$ ). Arrows show spotty GFP pattern in GFP- $\Delta$ Np63-expressing outgrowths. Scale bars: (b, c) $0.5 \mathrm{~mm}$; (d, e) $50 \mu \mathrm{m}$. (f-i) Double immunofluorescence for SMA (f and $\mathbf{h}$, left panels) and GFP (f and $\mathbf{h}$, middle panels). GFP control-infected MMECs are present both in SMA $(+)$ and SMA $(-)$ compartments (f right panel, $\mathbf{g}$ ), whereas the rare GFP- $\triangle N p 63$-infected MMECs that contribute to outgrowth are SMA $(+)$ (arrows in $\mathbf{h}$ and $\mathbf{i}$ ), scale bar: $100 \mu \mathrm{m}$

differentiation along specific lineage (Figure 8, full arrows). In either scenario, activation of Notch signaling triggers a transition to luminal progenitors by downmodulating $\Delta \mathrm{Np} 63$ expression and associated decrease of basal markers. Increase in Notch signaling activity in luminal progenitor stage I cells results in luminal progenitor stage II cells with a CD24 ${ }^{\text {hi }}$ phenotype and complete loss of $\Delta \mathrm{Np} 63$ expression. As luminal progenitor stage II cells differentiate into mature luminal cells, Notch signaling is, however, reduced, as suggested by our analysis of the TNR reporter mouse with loss of GFP signal in the cells of the mature ducts. This interpretation is in line with the model of transient Notch activation driving luminal cell fate proposed by Raouf et al. ${ }^{10}$ Thus, in accordance with the proposed hierarchical transition from bipotential progenitors, with concomitant reduction to either luminal or myoepithelial progenitor cells, ${ }^{9}$ our data reveal that activation of Notch signaling in bipotential progenitors with concomitant reduction in p63 expression and activity (Figure 8, full arrow) can specify a luminal progenitor cell fate characterized by decreased $\Delta \mathrm{Np} 63$, ITGA6, and ITGB1 expression, whereas the persistent $\Delta \mathrm{Np63}$ expression and attendant low Notch activity is required to maintain the multi-potential progenitor state and/or to favor myoepithelial differentiation.

In a broader context, we note that during pubertal ductal elongation, proliferation and cell fate determination occur specifically at the growing tips of the ducts, whereas at other stages, in particular pregnancy, proliferation is spread all over the ductal system. Previous studies of the RBPfl/fI.MMTV-Cre mouse model showed that mammary glands looked normal until mid-pregnancy, suggesting that Notch function is not important in puberty. ${ }^{30}$ However, our finding that Notch 
signaling activity in vivo is specifically increased during pubertal ductal morphogenesis points to the possible importance of this pathway also at this stage, while it could still be active at lower levels at other stages. In fact, using the same mouse model as those in the previous studies, but
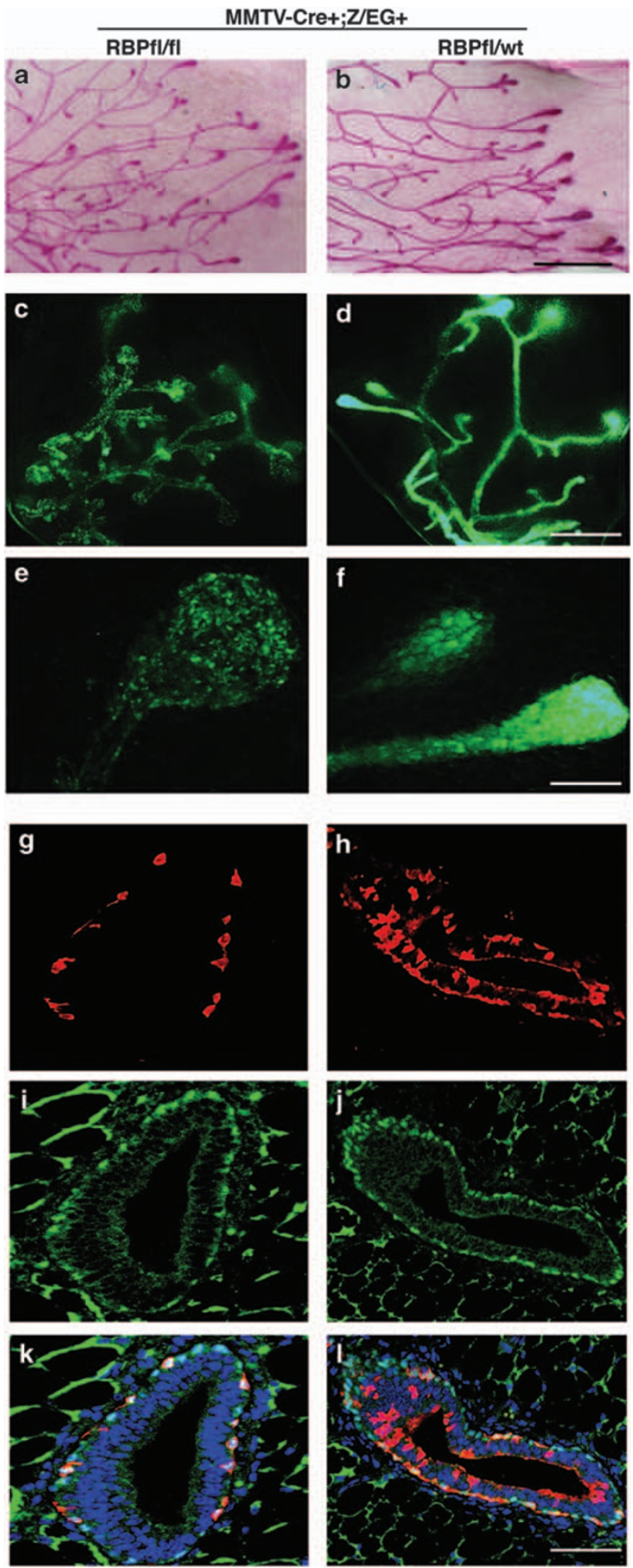

adding a GFP reporter to visualize $R B P$-j $\kappa$ deletion, we found that in the apparently normal mammary glands before pregnancy, cells with intact Notch signaling had been selected. Few RBP-j $\kappa$-deficient cells, which are GFP positive, were found and these were limited to the basal compartment. This suggests that the appearance of an overt phenotype in RBPfI/ fl.MMTV-Cre females only during pregnancy $^{30}$ is more likely a consequence of the increased and more widespread expression of Cre under MMTV control at this time than an essential function of Notch/RBP-j $\kappa$ limited to pregnancy. Consistent with this conclusion is the finding that expression of a dominant-negative Xenopus suppressor of hairless (RBP-jk homolog) gene impaired both pubertal ductal outgrowth and alveologenesis during pregnancy. ${ }^{38}$

The parallels of our findings in HBECs from multiple donors and in mouse point to a central and conserved antagonistic role of Notch and $\Delta \mathrm{Np} 63$ in breast epithelial homeostasis. With Notch signaling implicated in breast carcinogenesis, ${ }^{15-16}$ the question arises whether deregulation of this antagonism has a role in tumorigenesis. The Notch pathway has been targeted and $\gamma$-secretase inhibitors are currently in clinical trials. Will they affect cell type specification in tumors and/or the normal breast epithelium in treated patients?

\section{Materials and Methods}

Primary cell culture and viral infection. Normal human breast tissue was obtained from women undergoing reduction mammoplasties, with no previous history of breast cancer, who gave informed consent. All samples were confirmed by histopathological examination to be free of malignancy. Primary HBECs prepared from these specimens were infected at passage 1 or 2 with high-titer amphotropic retro- or lentiviruses as described. ${ }^{39}$ For selection, neomycin $(400 \mu \mathrm{g} / \mathrm{ml})$ or puromycin $(2 \mu \mathrm{g} / \mathrm{ml})$ were applied. For growth analysis, at each passage infected HBECs were plated at equal numbers, stained with $0.5 \%$ Crystal violet (Sigma, St. Louis, MO, USA) or counted in parallel, and population doublings were determined and used to calculate total cell numbers. For immunofluoresence, HBECs were cultured in Lab-Tek II-CO ${ }^{2}$ chamber slide system (NUNC, Thermo Fisher Scientific, Langenselbold, Germany). Proliferation was assessed by immunostaining for Ki67 with anti-Ki67 (1:500; Neomarkers, Lab Vision Products Thermo Fisher Scientific, Fremont, CA, USA) or BrdU incorporation with anti-BrdU ( 1 : 300; Oxford Biotechnology, Oxford, UK) after $4 \mathrm{~h}$ of incubation with $50 \mu \mathrm{M} \mathrm{BrdU}$. To activate Notch signaling shortly, HBECs were infected with inducible NICD-ER virus and grown on selection medium containing neomycin. HBECs were treated 7 days after infection with $1 \mu \mathrm{M} 4-\mathrm{OH}$-tamoxifen (Sigma) or ethanol as control for $8 \mathrm{~h}$.

Cell separation. Single cell suspensions of HBECs were prepared as described $^{39}$ and labeled with anti-CD10/RPE antibody $\left(10 \mu \mathrm{l}\right.$ for $1 \times 10^{6}$ cells; DAKO, Glostrup, Denmark; clone SS2/36) for $30 \mathrm{~min}$ at room temperature. Labeled HBECs were washed with PBS, $2 \%$ bovine serum albumin, incubated with anti-PE micro beads ( $10 \mu l / 10^{6}$ cells; Miltenyi Biotec, Bergisch Gladbach, Germany) for $30 \mathrm{~min}$ at room temperature and separated by MACS columns placed in a MiniMACS Separator (Miltenyi Biotec) according to manufacturer's protocol.

Figure 7 Canonical Notch signaling is required for luminal cell fate. (a, b) Whole mount stereomicrographs of mammary glands from 5-week-old littermates, either MMTV-cre.Rbpfl/fl (a) or MMTV-cre.Rbpfl/wt (b). Scale bar: $2 \mathrm{~mm}$. (c-f) Fluorescent stereomicrographs of mammary glands from 4-week-old MMTV-cre.Z/EG transgenic mice on $R b p f l / f l(\mathbf{c}, \mathbf{e})$ or $R b p f l / w t$ background $(\mathbf{d}, \mathbf{f})$. Scale bar: $(\mathbf{c}, \mathbf{d})$ $0.5 \mathrm{~mm}$; (e, f) $100 \mu \mathrm{m}$. GFP ( $\mathbf{g}$ and $\mathbf{h}$ ) and p63 (i and j) immunofluorescence on histological sections of mammary glands from MMTV-cre.Z/EG double transgenic mice, either $R b p f l / f l(\mathbf{g}, \mathbf{i}, \mathbf{k})$ or $R b p f / / w t(\mathbf{h}, \mathbf{j}, \mathbf{l})$. Note that in $R b p f / / w t$ double transgenic mice, GFP $(+)$ cells are in both p63-positive and -negative compartments (I), whereas in the Rbpfl/fl double transgenic epithelium, they are only in the p63-positive compartment (k). Scale bar: $100 \mu \mathrm{m}$ 


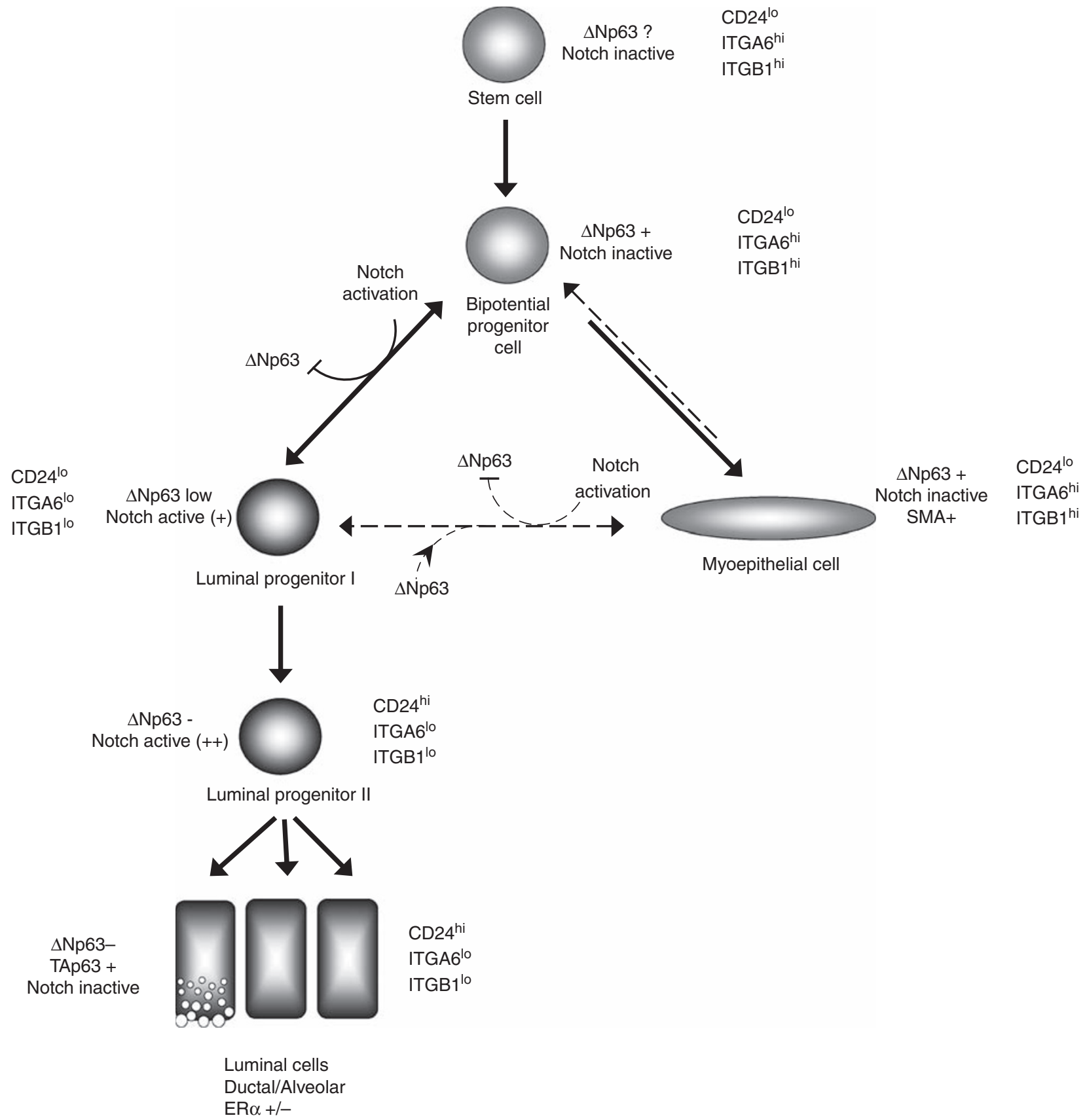

Figure $8 \Delta N$ N63/Notch antagonism in the regulation of breast epithelial cell fate. The putative stem cell gives rise to a bipotential progenitor cell that can take a myoepithelial or luminal cell fate. Notch activation in the bipotential progenitor cell specifies differentiation along the luminal cell lineage. As a result, a CD24lo cell with decreased p63 expression forms and the luminal progenitor stage I cell is determined. Continued and incremental Notch activation results in a luminal progenitor stage II cell, characterized by a CD24hi phenotype and lack of $\Delta \mathrm{Np63}$. This cell in turn gives rise to various differentiated luminal cells that have no detectable Notch activity. Transition of myoepithelial cells into luminal cells may occur directly or through a progenitor stage (dotted arrows)

FACS. Mouse mammary epithelial cells were prepared as described ${ }^{2,8}$ without pre-plating. Dead cells were excluded by 7 -amino-actinomycin-D staining (1:1000; Invitrogen, Paisley, UK). Cocktail of biotin-labeled anti-CD31 (clone MEC 13.3; 1:500; BD Biosciences, Erembodegem, Belgium), anti-CD140a (clone APA5; 1:500; eBiosciences, Hatfield, UK), anti-TER119 and anti-CD45 (1:50 and 1:1000, respectively; gift from Anne Wilson, Ludwig Institute, Lausanne, Switzerland), streptavidin-APC ( $0.06 \mu \mathrm{g}$ for $1 \times 10^{6}$ cells, eBiosciences), and PE- conjugated anti-mouse CD24 (clone M1/69; $0.5 \mu \mathrm{g} / \mathrm{ml}$; BD Biosciences) were used for stromal and epithelial cells. BD FACSAria (I) Cell Sorting System (BD Biosciences) was used for sorting.

Mammary gland reconstitution assay. Mouse mammary epithelial cells were isolated from 2-month-old mice, spin infected with high-titer lentivirus on day 2 in culture as described, ${ }^{40}$ and 50000 control and $\triangle$ Np63-infected MMECs were 
injected into contra lateral fat pads of 3-week-old mice divested of endogenous epithelium. Engrafted glands were analyzed 3 months later.

Viral constructs. High NICD expression levels were obtained with MSCVNICD retrovirus using CMV (cytomegalovirus) promoter. ${ }^{39}$ For low-level expression, NICD CDNA was subcloned into psd64, lentiviral vector that uses human PGK promoter using Gateway LR Clonase II Enzyme Mix (Invitrogen).

Protein preparation and immunoblotting. Cells were lysed in RIPA buffer and sonicated. Total protein $(20-40 \mu \mathrm{g})$ was subjected to SDS/PAGE followed by immunoblotting with anti-p63 (clone 4A4; 1:200; Neomarkers), antiCK14 (1: 1000; Neomarkers), anti-CK18 (clone Ab1, DC10; 1 : 2000; Neomarkers), anti- $\gamma$-tubulin, (1: 10000; Sigma), anti-ITGA6 (1: 200; Abcam, Cambridge, UK) antiITGB1 (clone 18; 1:2500; BD Biosciences), and anti-ITGB4 (clone 7; 1:250; BD Biosciences).

RNA isolation and qRT-PCR. Total RNA obtained from HBECs was isolated using RNeasy (Qiagen AG, Hombrechtikon, Switzerland), cDNA was synthesized using random $p(d N)_{6}$ primers (Roche Diagnostics $A G$, Rotkreuz, Switzerland) and MMLV reverse transcriptase (Invitrogen). Semi-quantitative real-time RT-PCRs (QRT-PCR) was performed with SYBR Green PCR Core Reagents System (Qiagen) on an iCycler real-time PCR detection system (Bio-Rad Laboratories AG, Reinach, Switzerland). Primers: $\triangle N p 63$, Hes6 ${ }^{10}$, Hey $2^{27}$, TAp63 5'-GTCCCAGAGCACACAGACAA-3', 5'-TGCGGATACAGTCCAT GCTA-3', total p63 5'-AGCAGCAAGTTTCGGACAGT-3', 5'-TGCTGTTGCCTGT ACGTTTC-3', CK14 5'-CACAGCCACAGTGGACAATG-3', 5'-GGCTCTCAATCT GCATCTCC-3', CK18 $5^{\prime}$-CACAGTCTGCTGAGGTTGGA-3', 5'-GAGCTGCTCCAT CTGTAGGG-3', CD24 5'-CTGCTGGCACTGCTCCTAC-3', 5'-ACCACGAAGAGA CTGGCTGT-3', ITGA6 5'-GGCGAGCAAGCTATGAAATC-3', 5'-AAAGCAACCAT TTCCCATTG-3', ITGB1 $5^{\prime}$-GGTCCAACCTGATCCTGTGT-3', 5'-AGCAGTAATGC AAGGCCAAT-3', ITGB4 5'-ACTGACCCGCTCAGAACACT-3', 5' -CTCCTGCCAG CTCACTCTG-3', NOTCH1 $5^{\prime}$-CTGAAGAACGGGGCTAACAA-3', $5^{\prime}$-CAGGTTGTA CTCGTCCAGCA-3', Hey $15^{\prime}$-GGGAGGGGAACTATATTGAATTTT-3', 5'-ATTTGT GAATTTGAGATCCGTGT-3', TBP 5'-TAGAAGGCCTTGTGCTCACC-3', 5'-TCTG CTCTGACTTTAGCACCTG-3'.

Total RNA from equal numbers of MMECs was isolated with PicoPure RNA isolation kit (Arcturus, Mountain View, CA, USA). Amplified cDNA was prepared with WT-Ovation RNA Amplification System (NuGEN, Bemmel, The Netherlands). Primers: GFP 5'-GCACGACTTCTTCAAGTCCGCCATGCC-3', 5'-GCGGATCTTG AAGTTCACCTTGATGCC-3', p63 5'-CCTTATGAGCCACCACAGGT-3', 5'-GCT GTCTTCATCTGCCTTCC-3', 36B4 5'-GTGTGTCTGCAGATCGGGTA-3', 5'-CAG ATGGATCAGCCAGGAAG-3', ITGA6 5'-CCCGTCTCCCTTGTCACTAA-3', 5'-CA ACAGCAAGATGGCTTGAA-3', ITGB 1 5'-TGCTGCTTGCAGGACTACAG-3', 5'-TC GAGACAGAGCAAGCATGT- $3^{\prime}$. For all results, two-tailed, paired Student's $t$-test was used to calculate statistical significance.

Mice. Transgenic Notch reporter mice ${ }^{31}$ were genotyped using GFP-specific primers 5'-TCCTTGAAGAAGATGGTGCG-3', 5'-AAGTTCATCTGCACCACCG-3'; MMTV-Cre, Rbpsuh $h^{f / f t}$, and Z/EG mice, as described. ${ }^{30,35}$ All mice were maintained and handled according to the Swiss guidelines for animal safety.

Mammary gland whole mount. Glands were processed as described. ${ }^{40}$ GFP images were acquired on Leica MZ16F stereoscope with Leica DC300F camera, whole mount images were taken on a Leica MZFLIII stereoscope (Leica, Wetzlar, Germany) with Pixelink PL-A622 camera (Pixelink, Ottawa, Canada).

Immunostaining. Mammary glands were fixed with $4 \%$ paraformaldehyde and paraffin embedded. Sections $(\mu \mathrm{m})$ were stained with the following antibodies: antiGFP (1: 100; Molecular Probes, Invitrogen), anti-p63 (clone 4A41:100; Molecular Probes, Invitrogen), anti-SMA (clone Ab1; 1: 200; Neomarkers); mouse-on-mouse immunodetection kit (Vector Laboratories, Burlingame, CA, USA) was used to block unspecific staining of mouse antibodies. Images were acquired on Leica DM2000 microscope with a Pixelink PL-A622C camera and Zeiss Axioplan 2-imaging fluorescence microscope (Göttingen, Germany) with Axiocam Mrm.

\section{Conflict of interest}

The authors declare no conflict of interest.
Acknowledgements. We thank A Ayyanan for technical assistance, and T Honjo and N Gaiano for kindly providing the RBPfl/WT and the TNR mice and $D$ Hanahan for critical reading of the paper. The p63sh RNA lentiviral, Pinco- $\Delta N p 63$, and inducible NICD vectors were kindly provided by W Hahn, P Dotto, and $U$ Just. This work was supported by funds from the NCCR Molecular Oncology, Oncosuisse, SNF-3100A0-112090.

1. Jones C, Mackay A, Grigoriadis A, Cossu A, Reis-Filho JS, Fulford L et al. Expression profiling of purified normal human luminal and myoepithelial breast cells: identification of novel prognostic markers for breast cancer. Cancer Res 2004; 64: 3037-3045.

2. Sleeman KE, Kendrick $\mathrm{H}$, Ashworth A, Isacke CM, Smalley MJ. CD24 staining of mouse mammary gland cells defines luminal epithelial, myoepithelial/basal and non-epithelial cells. Breast Cancer Res 2006; 8: R7.

3. Clarke RB, Howell A, Potten CS, Anderson E. Dissociation between steroid recepto expression and cell proliferation in the human breast. Cancer Res 1997; 57: 4987-4991.

4. Tanos T, Brisken C. What signals operate in the mammary niche? Breast Dis 2008; 29: $69-82$

5. Jones JC, Kurpakus MA, Cooper HM, Quaranta V. A function for the integrin alpha 6 beta 4 in the hemidesmosome. Cell Regul 1991; 2: 427-438.

6. Sonnenberg A, Calafat J, Janssen H, Daams H, van der Raaij-Helmer LM, Falcioni R et al. Integrin alpha 6/beta 4 complex is located in hemidesmosomes, suggesting a major role in epidermal cell-basement membrane adhesion. J Cell Biol 1991; 113: 907-917.

7. Shackleton M, Vaillant F, Simpson KJ, Stingl J, Smyth GK, Asselin-Labat ML et al. Generation of a functional mammary gland from a single stem cell. Nature 2006; 439: 84-88.

8. Stingl J, Eirew P, Ricketson I, Shackleton M, Vaillant F, Choi D et al. Purification and unique properties of mammary epithelial stem cells. Nature 2006; 439: 993-997.

9. LaMarca HL, Rosen JM. Minireview: hormones and mammary cell fate-what will I become when I grow up? Endocrinology 2008; 149: 4317-4321.

10. Raouf A, Zhao Y, To K, Stingl J, Delaney A, Barbara M et al. Transcriptome analysis of the normal human mammary cell commitment and differentiation process. Cell Stem Cell 2008; 3: 109-118.

11. Dontu G, Jackson KW, McNicholas E, Kawamura MJ, Abdallah WM, Wicha MS. Role of Notch signaling in cell-fate determination of human mammary stem/progenitor cells. Breast Cancer Res 2004; 6: R605-R615.

12. Bouras T, Pal B, Vaillant F, Harburg G, Asselin-Labat ML, Oakes SR et al. Notch signaling regulates mammary stem cell function and luminal cell-fate commitment. Cell Stem Cell 2008; 3: 429-441.

13. Bray SJ. Notch signalling: a simple pathway becomes complex. Nat Rev Mol Cell Biol 2006; 7: $678-689$

14. Gallahan D, Callahan R. Mammary tumorigenesis in feral mice: identification of a new int locus in mouse mammary tumor virus (Czech II)-induced mammary tumors. $J$ Virol 1987; 61: 66-74.

15. Pece S, Serresi M, Santolini E, Capra M, Hulleman E, Galimberti V et al. Loss of negative regulation by Numb over Notch is relevant to human breast carcinogenesis. J Cell Biol 2004; 167: 215-221.

16. Reedijk M, Pinnaduwage D, Dickson BC, Mulligan AM, Zhang H, Bull SB et al. JAG1 expression is associated with a basal phenotype and recurrence in lymph node-negative breast cancer. Breast Cancer Res Treat 2008; 111: 439-448.

17. Yang A, Kaghad M, Wang Y, Gillett E, Fleming MD, Dotsch V et al. p63, a p53 homolog at $3 q 27-29$, encodes multiple products with transactivating, death-inducing, and dominantnegative activities. Mol Cell 1998; 2: 305-316.

18. van Bokhoven $\mathrm{H}$, McKeon $\mathrm{F}$. Mutations in the p53 homolog p63: allele-specific developmental syndromes in humans. Trends Mol Med 2002; 8: 133-139.

19. Mills AA, Zheng B, Wang XJ, Vogel H, Roop DR, Bradley A. p63 is a p53 homologue required for limb and epidermal morphogenesis. Nature 1999; 398: 708-713.

20. Parsa R, Yang A, McKeon F, Green H. Association of $p 63$ with proliferative potential in normal and neoplastic human keratinocytes. J Invest Dermatol 1999; 113: 1099-1105.

21. Yang A, Schweitzer R, Sun D, Kaghad M, Walker N, Bronson RT et al. p63 is essential for regenerative proliferation in limb, craniofacial and epithelial development. Nature 1999; 398: $714-718$.

22. Signoretti S, Waltregny D, Dilks J, Isaac B, Lin D, Garraway L et al. p63 is a prostate basal cell marker and is required for prostate development. Am J Pathol 2000; 157: 1769-1775.

23. Barbareschi M, Pecciarini L, Cangi MG, Macri E, Rizzo A, Viale G et al. p63, a p53 homologue, is a selective nuclear marker of myoepithelial cells of the human breast. Am J Surg Pathol 2001; 25: 1054-1060.

24. Suh EK, Yang A, Kettenbach A, Bamberger C, Michaelis AH, Zhu Z et al. p63 protects the female germ line during meiotic arrest. Nature 2006; 444: 624-628.

25. Carroll DK, Carroll JS, Leong CO, Cheng F, Brown M, Mills AA et al. p63 regulates an adhesion programme and cell survival in epithelial cells. Nat Cell Biol 2006; 8: 551-561.

26. O'Hare MJ, Ormerod MG, Monaghan P, Lane EB, Gusterson BA. Characterization in vitro of luminal and myoepithelial cells isolated from the human mammary gland by cell sorting. Differentiation 1991; 46: 209-221.

27. Nguyen BC, Lefort K, Mandinova A, Antonini D, Devgan V, Della Gatta G et al. Crossregulation between Notch and p63 in keratinocyte commitment to differentiation. Genes Dev 2006; 20: 1028-1042. 
28. Dotto GP. Crosstalk of Notch with p53 and p63 in cancer growth control. Nat Rev Cancer 2009; 9: 587-595.

29. Schroeder T, Just U. Notch signalling via RBP-J promotes myeloid differentiation. EMBO J 2000; 19: 2558-2568.

30. Buono KD, Robinson GW, Martin C, Shi S, Stanley P, Tanigaki K et al. The canonical Notch/RBP-J signaling pathway controls the balance of cell lineages in mammary epithelium during pregnancy. Dev Biol 2006; 293: 565-580.

31. Mizutani K, Yoon K, Dang L, Tokunaga A, Gaiano N. Differential Notch signalling distinguishes neural stem cells from intermediate progenitors. Nature 2007; 449 351-355.

32. Daniel CW, Silberstein GB. Postnatal development of the rodent mammary gland. In: Neville MC, Daniel CW (eds). The Mammary Gland. Plenum Press: New York, 1987 pp 3-31.

33. Sapino A, Macri L, Gugliotta P, Pacchioni D, Liu YJ, Medina D et al. Immunophenotypic properties and estrogen dependency of budding cell structures in the developing mouse mammary gland. Differentiation 1993; 55: 13-18.

34. Daniel CW, Deome KB. Growth of mouse mammary glands in vivo after monolayer culture. Science 1965; 149: 634-636.
35. Novak A, Guo C, Yang W, Nagy A, Lobe CG. Z/EG, a double reporter mouse line that expresses enhanced green fluorescent protein upon Cre-mediated excision. Genesis 2000; 28: 147-155.

36. Stingl J, Eaves CJ, Zandieh I, Emerman JT. Characterization of bipotent mammary epithelial progenitor cells in normal adult human breast tissue. Breast Cancer Res Treat 2001; 67: 93-109.

37. Li N, Singh S, Cherukuri P, Li H, Yuan Z, Ellisen LW et al. Reciprocal intraepithelial interactions between TP63 and hedgehog signaling regulate quiescence and activation of progenitor elaboration by mammary stem cells. Stem Cells 2008; 26: 1253-1264.

38. Welm BE, Dijkgraaf GJ, Bledau AS, Welm AL, Werb Z. Lentiviral transduction of mammary stem cells for analysis of gene function during development and cancer. Cell Stem Cell 2008; 2: 90-102.

39. Ayyanan A, Civenni G, Ciarloni L, Morel C, Mueller N, Lefort K et al. Increased Wnt signaling triggers oncogenic conversion of human breast epithelial cells by a Notch-dependent mechanism. Proc Natl Acad Sci USA 2006; 103: 3799-3804.

40. Brisken C, Socolovsky M, Lodish HF, Weinberg R. The signaling domain of the erythropoietin receptor rescues prolactin receptor-mutant mammary epithelium. Proc Natl Acad Sci USA 2002; 99: 14241-14245.

\section{Supplementary Information accompanies the paper on Cell Death and Differentiation website (http://www.nature.com/cdd)}

